RU Дискурсивная деятельность А. С. Гинзберга по реформе системы высшего фармацевтического образования в России начала $\mathrm{XX}$ века

Воробьева С. А., Завершинская Н. А., Степанов С. В.

Аннотация. Цель исследования - раскрыть значение дискурсивной реформаторской деятельности русского педагога и ученого А. С. Гинзберга для создания современной системы высшего фармацевтического образования. В статье на основе контент-анализа педагогического наследия ученогопедагога раскрыта его позиция по проблеме институциализации системы высшего фармацевтического образования, определены особенности концептуализации назревших изменений фармацевтического образования второй половины XIX - начала XX века, дана характеристика педагогических взглядов А. С. Гинзберга. На основе компаративно-ретроспективного анализа показана преемственность современной системы подготовки фармацевтических кадров в Санкт-Петербургском химикофармацевтическом университете с идеями начала XX в. Новизна исследования: впервые охарактеризованы педагогическая деятельность А. С. Гинзберга и его взгляды на институциализацию высшего фармацевтического образования. В результате доказано, что педагогические идеи А. С. Гинзберга, высказанные в начале XX в., оказали значительное влияние на реформу высшего фармацевтического образования, создание системы подготовки кадров, которая существует в России и поныне.

\title{
A. S. Ginzberg's Discursive Activity on Reforming Higher Pharmaceutical Education System in Russia in the Early XX Century
}

\author{
Vorobieva S. A., Zavershinskaya N. A., Stepanov S. V.
}

\begin{abstract}
The research aims to shed light on importance of the discursive reform activity undertaken by the Russian teacher and scientist A. S. Ginzberg for creation of the modern system of higher pharmaceutical education. Basing on a content analysis of pedagogical heritage of the scientist and teacher, the article reveals his standpoint on the issue of institutionalisation of the higher pharmaceutical education system, identifies the features peculiar to conceptualisation of overdue changes in pharmaceutical education in the second half of the XIX - early XX century, describes A. S. Ginzberg's pedagogical views. On the basis of a comparative and retrospective analysis, the authors show continuity of the modern system of pharmaceutical specialists training at Saint Petersburg State University of Chemistry and Pharmacy with the ideas of the early XX century. The research is novel in that it is the first to characterise A. S. Ginzberg's teaching activity and his views on institutionalisation of higher pharmaceutical education. As a result, it is proved that A. S. Ginzberg's pedagogical ideas, expressed in the early XX century, had a significant impact on the reform of higher pharmaceutical education, creation of a training system that still exists in Russia today.
\end{abstract}

\section{Введение}

Актуальность исследования. Современный динамичный мир характеризуется стремительным развитием технологий, прошлое стремительно удаляется от нас, происходит утрата единства исторического времени с уходящими поколениями и забвением их ярких представителей. Пытаясь сохранить общую память народа, современность предается воспоминаниям и предпринимает усилия для того, чтобы оценить факты прошлого с позиций XXI века. Желание помнить помогает нам опираться на опыт предшественников в процессе трансформации и обновления общества и избегать возможных ошибок. Особенно это важно сейчас, когда перед Россией стоят фундаментальные задачи социальной модернизации, важнейшими составляющими которой являются реформа высшего образования и здоровьесбережение нации. 
В «Национальной доктрине образования в Российской Федерации», определяющей цели воспитания и обучения до 2025 года, подчеркивается, что система образования призвана обеспечить историческую преемственность поколений, сохранение, распространение и развитие национальной культуры [22]. Реализация поставленной задачи предполагает обращение к изучению традиций и новаций отечественной системы образования, осмысление путей ее реформирования с позиций непрерывности и преемственности. Понимание логики зарождения и развития института образования позволяет избежать противоречий в содержании, формах, методах обучения и обеспечить последовательность и системность современного педагогического процесса.

Замыслы и идеалы реформаторов отечественной системы фармацевтического образования рубежа XIX-XX веков приобретают для нас особую ценность сейчас, когда в соответствии со «Стратегией развития фармацевтической промышленности Российской Федерации на период до 2030 года» предполагается создать систему подготовки кадров для обеспечения потребностей фармацевтической отрасли, включая развитую образовательную и научную инфраструктуру [27]. В этих условиях может оказаться полезным созидательный опыт выдающихся педагогов, таких как Александр Сергеевич Гинзберг, по организации современной системы подготовки фармацевтических кадров в нашей стране.

Задачи исследования:

- охарактеризовать институт подготовки фармацевтических кадров посредством исторической институциализации системы фармацевтического образования;

- ретроспективно, на основе дискурсивной деятельности А. С. Гинзберга, определить особенности концептуализации назревших изменений фармацевтического образования второй половины XIX - начала XX века, выделить круг идей публично обсуждаемых реформационных проектов;

- проанализировать педагогические взгляды А. С. Гинзберга, подготовившие реорганизацию системы фармацевтического образования.

Методами исследования являются методы институционализма, системного анализа, педагогического компаративизма.

Целесообразность методологии исторического институционализма применительно к исследованию образования заключается в том, что она позволяет понять причины происходящих в образовательной среде событий, проследить законодательное закрепление тех или иных механизмов взаимодействия людей в области образования, раскрыть роль неформальных правил в образовании наряду с формально закрепленными в законодательстве подзаконными актами, выделить исторические этапы институционализации системы образования [5, с. 21].

Наряду с институциональным подходом ценной для предпринятого исследования является методология системного анализа. В широком смысле системный анализ представляет собой синтез методологии общей теории систем, системного подхода и системных методов обоснования и принятия решений [4, с. 261-262; 23, с. 39-43]. Основания общей теории систем заложил в 40-х годах XX века Л. Берталанфи. Современная стадия общесистемного подхода представлена рядом конкурирующих вариантов (М. Месарович, Р. Акоф, У. Росс Эшби, О. Ланге и др.) [3, с. 51-52].

Применяемый авторами данного исследования компаративистский подход позволил рассмотреть феномен фармацевтического образования в развитии, во временных срезах прошлое - настоящее - будущее, объяснить причины отставания сложившейся в России в XIX - начале XX века системы подготовки фармацевтических кадров по сравнению с более продвинутой западной моделью. При этом сравнение проводилось с помощью интерпретационных методов, на основе истолкования экспертных оценок образовательного процесса в нашей стране и за рубежом, которые были даны в статьях и публичных выступлениях выдающимся педагогом и ученым А. С. Гинзбергом. Безусловно, компаративистский подход в сочетании с методологией институционализма и системного анализа позволил авторам данного исследования грамотно решить поставленные перед ними задачи и достичь заявленной цели.

Теоретическую базу исследования составляют труды ученых и исследователей: А. С. Гинзберга [7-14], проанализировавшего причины кризиса русской фармации и предложившего проект реформирования системы фармацевтического образования, а также работы доктора фармацевтических наук, профессора И. А. Наркевича (в соавторстве) [20; 21], реконструировавшего жизненный путь А. С. Гинзберга; Н. Н. Аловой [1], предпринявшей попытку сравнительного анализа учебных планов провизорских курсов при российских вузах на рубеже XIX-XX веков, проследившей историю организации и работы Петроградского химико-фармацевтического института (ныне Санкт-Петербургский химико-фармацевтический университет); В. А. Куликова [18], воссоздавшего пройденный Россией процесс подготовки фармацевтических кадров от примитивного обучения аптекарскому делу в аптеке XVI века до академического фармацевтического образования в XIX веке; Н. Н. Коротеевой [16], рассмотревшей основные вехи истории фармацевтического образования в России XVII начала XX века; Н. Б. Лопатиной (в соавторстве) [19], проанализировавшей становление системы высшего фармацевтического образования в России от ее истоков до сегодняшнего дня; М. Н. Гурьяновой (в соавторстве) [15], исследовавшей историю нормативных требований к образованию фармацевтических работников и их профессиональной компетентности в XIX - начале XX века, а также рассмотревшей проблему формирования сознания фармацевтической общественности и его основного компонента - убеждения о необходимости высокого уровня профессионального фармацевтического образования.

Практическая значимость исследования заключается в том, что педагогические идеи А. С. Гинзберга по реформированию отечественной системы фармацевтического образования в условиях кризисного состояния фармацевтической отрасли на рубеже XIX - XX веков могут быть использованы в образовательном процессе 
для развития у выпускников фармацевтических вузов широкой общей и профессиональной культуры, навыков историко-педагогического, системного и критического мышления, способности к адаптации и профессиональной мобильности в условиях динамичной социальной трансформации России. Научный дискурс по исследуемой тематике будет содействовать синтезу педагогики высшей школы как мультидисциплинарной науки с историей фармации и фармацевтического образования [25, с. 119-124].

\section{Характеристика института подготовки фармацевтических кадров посредством исторической институциализации системы фармацевтического образования}

Проблема институциализации отечественной системы образования занимает важное место в проблемном поле целого ряда дисциплин - истории, философии, социологии, культурологии, политологии, экономики и, конечно, педагогики [5, с. 21 ; 6, с. 12-19; 25]. Институционализм оформился на рубеже XIX-XX веков и стал применяться в исследованиях разнообразных сторон общественной жизни [25]. Основные концепции и принципы институализации основываются на идеях Г. Спенсера, У. Самнера, М. Вебера, Ч. Пирса, Дж. Дьюи, Т. Парсонса и других теоретиков [23, с. 51-52]. Исторический институционализм проявляет интерес как к формальной организации, так и неформальным правилам и процедурам, структурирующим образы действия. Данный метод определяется главной посылкой, состоящей из постулирования идеи зависимости институтов от их прошлой траектории развития [17, с. 211-212].

История развития фармации как науки и как системы подготовки фармацевтических кадров в СанктПетербургском химико-фармацевтическом университете (СПХФУ) представлена в целом ряде публикаций, число которых особенно пополнилось в связи с празднованием 100-летия СПХФУ в 2019 году [20; 21; 26]. Ключевое место в этой истории по праву принадлежит первому ректору - Александру Сергеевичу Гинзбергу, усилиями которого и при участии которого была создана современная система подготовки фармацевтических кадров и один из первых специализированных фармацевтических вузов (в то время носивший название Петроградского химико-фармацевтического института).

Становление системы подготовки фармацевтических кадров в России происходило на протяжении длительного исторического времени и сопровождалось значительными трудностями и противоречиями. Не случайно на рубеже XIX-XX веков русская фармация оказалась в тяжелом кризисном положении, связанном с неразвитостью химико-фармацевтической промышленности и фармацевтического образования. Отправной вехой для понимания текущего состояния дел в отрасли, по утверждению А. С. Гинзберга, изложенному в докладе «К вопросу об общем и специальном образовании фармацевтов» на Российском фармацевтическом съезде, следует считать 1845 год. Названная дата в качестве точки отсчета связана с принятием закона от 18 декабря 1845 года, в котором устанавливались новые правила организации системы фармацевтического образования. Сложившиеся в соответствии с этими правилами формы подготовки фармацевтов просуществовали в неизменном виде почти 70 лет, вплоть до десятых годов XX века [8].

Начиная с 1840-х годов и вплоть до конца XIX - начала XX века подготовка фармацевтических кадров в России функционировала в форме двухступенчатой системы обучения: начальной (ремесленной) ступени и академической (вузовской). Начальное фармацевтическое образование осуществлялось в аптеках путем ученичества. От поступавших в аптеку учеников требовалось наличие общего образования в объеме 4 классов гимназии. Обучение в аптеках носило кустарный, ремесленный характер. Аптекарские ученики должны были знать латинский язык, переводить фармакопею, уметь писать на латинском языке рецепты, готовить по правилам фармакопеи лекарства и составлять в лаборатории лекарственные средства [15, с. 48].

Во второй половине 1870-х годов была предпринята реорганизация аптечного ученичества на основе организации государственной системы низших фармацевтических школ, в которых должны были учиться выпускники гимназий. Проект реформ предусматривал отказ от ремесленного обучения и создание системы фармацевтических школ (низших и высших) с полноценным сроком обучения. Однако существовавшая система начального профессионального обучения фармацевтов в форме аптекарского ученичества в основном сохранилась в неизменном виде, что не давало возможности качественно изменить организационную структуру подготовки фармацевтических кадров.

С 1885 года право на фармацевтическое образование получили женщины, им было разрешено поступать в качестве учениц в аптеку, а с 1895 года Медицинский департамент разрешил совместные занятия в двухгодичных курсах при аптеках мужчин и женщин. Предоставление женщинам возможности на фармацевтическое образование сопровождалось серьезными ограничениями: занятия в дневное время, проживание вне аптек, подготовка к экзаменам частным образом. Лишь во время Русско-японской войны женщины получили свободный доступ в аптеки [16, с. 165].

Академическая ступень фармацевтического образования включала теоретическую подготовку обучающихся, в соответствии с этим для фармацевтов читался курс лекций в высшей школе. Фармацевтам, получавшим высшее фармацевтическое образование и успешно прошедшим испытания, присваивались три фармацевтических звания - аптекарского помощника (гезеля), провизора и магистра фармации (которое было введено вместо звания аптекаря).

Особенностью системы высшего фармацевтического образования являлось то, что при университетах отсутствовали фармацевтические факультеты. Фармацевтам предоставлялось право быть вольными слушателями 
на медицинских факультетах, на которых они не были полноправными студентами. Однако их образование, основанное на аптечном ученичестве и обучении в университетах на правах вольных слушателей, было максимально приближено к медицинскому образованию. В целом уровень подготовки фармацевтов был достаточно высоким [18, с. $103 ; 19$, с. 82$]$.

С 1915 года стали открываться самостоятельные химико-фармацевтические отделения при некоторых учебных заведениях: Психоневрологическом институте, Женском медицинском институте с курсом обучения в 3 года. Наряду с этим были предприняты так и не увенчавшиеся успехом попытки создать фармацевтические отделения при медицинских и химических факультетах университетов. В целом позитивные начинания, однако, не снимали с повестки дня вопроса о реформировании системы подготовки фармацевтических кадров и повышении уровня их образования.

Таким образом, сложившийся в России институт подготовки фармацевтических кадров характеризовался консерватизмом и невосприимчивостью к нововведениям. Отсутствие при российских университетах фармацевтических факультетов и замещение их провизорскими курсами не соответствовали реалиям XX века.

\section{Дискурсивная деятельность А. С. Гинзберга по концептуализации изменений в высшем фармацевтическом образовании рубежа XIX - начала XX века}

Отсутствие у фармацевтов полноценных факультетов в системе отечественной высшей школы неблагоприятно отражалось на подготовке кадров для фармацевтической отрасли. Для понимания причин отсутствия фармацевтических факультетов при российских университетах и исправления исторических ошибок необходимо было проанализировать становление и развитие русской фармации за прошедший период. С результатами такого исследования выступил в 1901 году А. С. Гинзберг на заседании Санкт-Петербургского фармацевтического общества. В речи «Очерк развития научной фармации в России за 200-летний период» А. С. Гинзберг обратил внимание общественности на целый комплекс факторов и причин, по которым в России не сложилась самостоятельная институция фармацевтических факультетов и фармацевтических высших школ. Речь шла:

- во-первых, о несамостоятельности корпорации фармацевтов в решении вопросов образования вследствие чрезмерной государственной опеки;

- во-вторых, о высоких конкурентных школьных преимуществах аптек и их аптечных лабораторий как центров научной и учебной деятельности перед университетами в условиях расцвета химии сто двадцать лет тому назад, что обусловило индифферентность фармацевтической корпорации «к созидаемому школьному образованию» [13, № 16, с. 273];

- в-третьих, о том, что «расцвет технической химии в середине XIX столетия постепенно лишает аптеку многих областей ее химико-фармацевтической деятельности, медленно и неукоснительно лишает ее научного содержания, все более и более суживая рамки ее деятельности. Воспитанная односторонней опекой, несамостоятельность корпорации лишает аптеки способности к завоеванию новых областей деятельности, вместо неизбежно теряемых, под натиском исторического развития, науки, техники и хода событий» [Там же];

в-четвертых, об ошибочных позициях государственных органов по вопросам фармацевтического образования, которые усугубили кризисные явления русской фармации. К тяжелым последствиям для фармацевтического образования А. С. Гинзберг отнес, в частности, снижение образовательного ценза студентов фармацевтического отделения Медико-хирургической академии, сокращение четырехлетнего курса обучения сначала до трехлетнего, потом до двухгодичного и в конечном итоге закрытие фармацевтического отделения академии [Там же].

Нововведения, практикуемые в высшей школе по вопросу подготовки фармацевтических кадров, характеризовались непоследовательностью действий и непроработанностью концепции изменений. Если в Европе высшее фармацевтическое образование складывалось естественным путем, своевременно модернизируясь, отвечая на научные запросы своей нации, являясь результатом систематического развития общества, отражением его повышающейся культуры, то в России оно, по словам А. С. Гинзберга, насаждалось искусственно. Условия для развития преподавания фармации в российских университетах, за исключением Юрьевского (Дерптского), складывались «менее благоприятно, как под влиянием либо недостатка в людях и деньгах, так и под влиянием больших или меньших перерывов между деятельностью одного и другого энергичного борца в пользу расширения и улучшения преподавания» [Там же]. Одним из таких борцов был сам Александр Сергеевич Гинзберг, который принимал самое непосредственное участие в развернувшейся на рубеже XIX-XX веков публичной дискуссии по вопросу о реформе фармацевтического образования, а также в подготовке и реализации проектов такой реформы.

Вопросы, которые ставились и решались в предлагаемых для обсуждения проектах реформы фармацевтического образования, охватывали следующий круг проблем: целесообразность таких ступеней фармацевтического образования, как высшая и/или средняя; обязательность или факультативность теории в фармацевтическом образовании как предшествующей практике формы; оправданность потребности в аптечном ученичестве; аргументированность претензий на требование стажа аптекарского помощника и определение его длительности; условия и возможности открытия фармацевтических школ, самостоятельного фармацевтического института, факультета, отделения; наличие и характер образовательного ценза для поступления в высшее учебное заведение; длительность прохождения курса в высшем учебном заведении; обоснованность 
введения практического стажа после окончания вуза до получения диплома о высшем образовании; приемлемость предлагавшихся наименований фармацевтических степеней и званий и т.д. [1, с. 10].

В ходе публичного обсуждения проблем фармацевтического образования между его участниками были достигнуты соглашения по принципиальным вопросам и выработана солидарная с мнениями авторитетных представителей профессионального фармацевтического сообщества позиция. В 1913 году на Российском фармацевтическом съезде эта позиция была озвучена А. С. Гинзбергом в докладе «К вопросу об общем и специальном образовании фармацевтов». Критически отзываясь о программах высшего специального образования, А. С. Гинзберг подчеркивал, что учебные планы совершенно не соответствуют тем требованиям, которые в настоящее время можно и должно предъявлять к образованному фармацевту. Для подготовки образованного фармацевта, по его мнению, необходимо было перейти к правильному планированию дальнейшего специального образования [8].

Таким образом, первые десятилетия XX века отмечены острыми публичными дискуссиями о путях реформирования фармацевтического образования. Активным участником дискурс-коммуникации был А. С. Гинзберг, выступивший с анализом причин кризиса русской фармации.

\section{Педагогические идеи А. С. Гинзберга по реорганизации системы фармацевтического образования}

Система российского фармацевтического образования, несмотря на огромные усилия передовых сил общественности по ее трансформации в нулевые и десятые годы XX века, оставалась консервативной и не отвечающей социальным вызовам того времени. В 1915 году на заседании Петроградского фармацевтического общества А. С. Гинзберг в докладе «О новых направлениях в вопросе фармацевтического образования» констатировал факт сложившихся неблагоприятных условий для реформы. «Краеугольным камнем реформы всего фармацевтического дела и строя, уже много лет застывших в своей устаревшей форме» [10, № 42, с. 410], А. С. Гинзберг объявил правильно поставленное и последовательно построенное образование фармацевтов. Вызревание этой идеи происходило неодномоментно, к ней А. С. Гинзберг последовательно обращался и раньше в своих публичных выступлениях, сделанных в нулевые годы XX века: «К вопросу об однообразии систематики (с дидактической точки зрения) отделов фармации в современных медицинских и фармацевтических школах», «О постановке преподавания общей и прикладной химии в наших медицинских школах», в статье для энциклопедического словаря «Химия фармацевтическая» и других. А. С. Гинзберг неоднократно подчеркивал полное отсутствие общего плана и какой-либо последовательности в деятельности кафедр и лабораторий во многих университетах, занимающихся подготовкой кадров врачей и фармацевтов, указывал на необходимость более тщательного систематизирования фармацевтических дисциплин. Так, речь шла о том, что в целом ряде университетов нет особой кафедры фармацевтической химии, а есть кафедра фармации, под названием которой боязливо прячется предмет фармацевтической химии. Более целесообразно, по мнению А. С. Гинзберга, чтобы из всей суммы фармацевтических знаний были выделены следующие кафедры в высших школах: кафедра фармацевтической химии и кафедра фармакогнозии, которые важны как для фармацевтов, так и для студентов-медиков. При этом фармацевтическая химия и фармакогнозия должны преподаваться по-разному студентам-медикам и фармацевтам. Если первым должны преподаваться основы обоих предметов, то для вторых материал должен быть значительно расширен, переплетаясь с соседними областями этих наук. «Обе эти кафедры для фармацевтов при относительной бедности по количеству предметов, введенных в курс фармацевтического образования, должны охватывать гораздо большие горизонты» [9, с. 3].

Химическое образование студентов-медиков А. С. Гинзберг также считал неудовлетворительным, поскольку не усматривал рационализма и связности в деятельности кафедр как по неорганической и органической химии, так и по прикладным медико-химическим предметам (физиологическая, фармацевтическая химия, гигиена), занимавшим, как правило, второстепенное положение в медицинских высших школах. А. С. Гинзбергом был предложен план реформирования химического образования, который бы способствовал «приобретению студентом-медиком цельного и осмысленного химического образования» [2, с. 1257-1260; 12, с. 3].

Участвуя в разработке плана высшего фармацевтического образования и неоднократно представляя его в десятые годы XX века в своих докладах на фармацевтических съездах и заседаниях фармацевтического общества, А. С. Гинзберг выступал за увеличение срока университетского образования фармацевтов до трехлетнего или даже четырехлетнего курса; за предоставление советам учебных заведений (с правом преподавания высших фармацевтических курсов) самостоятельно разрабатывать программы и учебные планы преподавания фармации; за подготовку кадров для химико-фармацевтической промышленности; за годичный аптечный стаж абитуриентов до поступления на высшие фармацевтические курсы при общем образовании не ниже полного среднего учебного заведения и против двухлетних (низших) фармацевтических школ с последующим годичным практическим стажем в аптеке как ступени для поступления на высшие фармацевтические курсы; за предоставление возможности фармацевтам, прошедшим годичный аптечный стаж, сдать «особый экзамен» при фармацевтическом отделении высшего учебного заведения, соответствующий экзамену на аптекарского помощника; за введение годичного стажа в аптеке для окончивших высшие фармацевтические курсы (либо двухгодичного при отсутствии первого аптечного стажа) как обязательного для получения звания провизора.

В качестве ориентира при организации правильно поставленного и последовательно построенного образования фармацевтов А. С. Гинзберг предлагал общий план образования в Психоневрологическом институте, при котором педагог-реформатор открыл в 1915 году химико-фармацевтическое отделение и председателем 
которого был до его закрытия в 1919 году. Учебный план фармацевтического отделения наряду с общими предметами предполагал включение технических, технико-химических и прикладных специальных курсов (товароведение, культура медицинских растений, машиноведение, фармацевтическое законодательство, химическая технология, разные технохимические производства и т.д.).

Важной особенностью преподавания в институте, по замечанию А. С. Гинзберга, являлось не только профессиональное образование, но и довольно широкое гуманитарно-социологическое. Так, полагалось обоснованным включение для студентов-фармацевтов в общий план образования Психоневрологического института весьма широкого спектра гуманитарных дисциплин: логики (с теорией познания), истории, социологии, истории русской литературы, истории искусства, теории права и государства, истории новой философии и др. [11, с. 770-772].

Особую озабоченность выражал А. С. Гинзберг по вопросу о подготовке кадров для химико-фармацевтической промышленности и считал вполне приемлемым министерский проект о желательности введения на физикоматематических факультетах университетов особых химических отделений, в том числе со специализацией в области фармацевтической химии. Обсуждая приведенный примерный учебный план на химикофармацевтических курсах, Гинзберг сожалел, что такие вузы, как Петроградский университет, Петроградский женский медицинский институт, не приступают к реализации проекта. Как прекрасный методист, ученый предложил для включения в учебные планы российских медицинских школ конкретный перечень химических дисциплин, в число которых входили органическая, неорганическая, аналитическая, физиологическая, фармацевтическая химия. Распределение этих дисциплин по курсам и периодам обучения А. С. Гинзберг убедительно обосновал с тем, чтобы «успешно содействовать приобретению студентом-медиком “цельного и осмысленного химического образования”» [Там же].

Опираясь на позитивный опыт западных стран, А. С. Гинзберг выступал за рациональное совмещение теоретического и практического преподавания, подчеркивая пользу от деятельности аптеки и аптечных лабораторий как для сохранения здоровья населения, так и для практической подготовки обучающихся в рамках высшего образования. Многообразные виды деятельности образцового фармацевта в аптеке указывают, по мнению А. С. Гинзберга, в каком направлении следует конструировать высшее/среднее образование [8; 14].

Итогом многолетней деятельности А. С. Гинзберга по реформированию фармацевтического образования стало образование в 1919 году Петроградского химико-фармацевтического института (ПХФИ), который сумел стать, по словам его первого ректора А. С. Гинзберга, центром научной и научно-практической фармацевтической мысли [14]. В письме заместителю Народного комиссариата по просвещению от 20 сентября 1919 года профессор А. С. Гинзберг, формулируя задачи, стоящие перед институтом, писал, что ПХФИ должен «рационально поставить фармацевтическое образование и подготовить опытных деятелей для насаждения отечественной химико-фармацевтической промышленности, культуры лекарственных растений и их обработки, а также для административного хозяйственного персонала и преподавания в средних профессиональных фармацевтических школах» [7, д. 31.2, л. 9].

Сегодня Санкт-Петербургский химико-фармацевтический университет достойно продолжает воплощать в жизнь заветы и идеалы своего основателя и выдающегося педагога-реформатора Александра Сергеевича Гинзберга. Педагогический опыт талантливого новатора по рациональной организации высшего фармацевтического образования не утратил своей значимости для современности. В начале XXI века, как и в начале XX века, вновь стала злободневной мысль А. С. Гинзберга о «правильно поставленном и последовательно построенном образовании фармацевтов» [10, № 42, с. 410].

\section{Заключение}

В условиях кризисного состояния российской фармацевтической отрасли и серьезных проблем с подготовкой для нее образованных фармацевтических кадров Александр Сергеевич Гинзберг выступил как серьезный реформатор отечественной системы фармацевтического образования и всего фармацевтического дела. Размышляя над причинами кризиса русской фармации, он обратил внимание на консерватизм сложившихся институтов подготовки фармацевтических кадров и их несоответствие развитию науки, техники, культуры $\mathrm{XX}$ века. Участвуя в публичной коммуникации по вопросу реформирования высшего фармацевтического образования, А. С. Гинзберг представил идеи об ошибочности, непоследовательности и противоречивости концепций изменений, об отсутствии условий для возникновения при российских университетах фармацевтических факультетов и высших фармацевтических школ, о несоответствии программ высшего специального образования требованиям подготовки образованного фармацевта. Являясь опытным педагогом-новатором, он разработал проект правильно поставленного и последовательно построенного образования фармацевтов и участвовал в его реализации.

Теоретической матрицей для проектирования системы фармацевтического образования, отвечающей духу времени, развитию науки, медицины и химии, стала для А. С. Гинзберга гипотетическая модель «образцового фармацевта» или «рационально образованного фармацевта» как в деле сохранения народного здоровья, так и в создании и развитии отечественной химико-фармацевтической промышленности. Ориентируясь на эту модель фармацевта как хорошо подготовленного профессионала с широким гуманитарным кругозором и отчетливым пониманием своих гражданских функций, Гинзберг обосновал спектр направлений, в рамках которых следует конструировать высшее и среднее фармацевтическое образование. Достойным воплощением 
его замыслов стало создание и развитие Санкт-Петербургского химико-фармацевтического университета как наследника и продолжателя Петроградского (Ленинградского) химико-фармацевтического института.

Научные исследования по истории фармацевтической педагогики и личностного педагогического дискурса являются перспективными, поскольку позволят сохранить от забвения лучшие традиции отечественного фармацевтического образования, имена их создателей. Благодаря воссозданию истории подвижнической деятельности педагогов и руководства СПХФУ, других фармацевтических вузов обеспечивается преемственность института образования и вносится вклад в формирование чувства гражданственности у выпускников.

\section{Источники | References}

1. Алова Н. Н. Подготовка и использование фармацевтических кадров (XIX-XX-XXI века) на примере СанктПетербурга: автореф. дисс. ... к. фарм. н. СПб., 2004. 24 с.

2. Антипин И. С., Казымова М. А. Органическая химия. История и взаимная связь университетов России // Журнал органической химии. 2017. Т. 53. Вып. 9. С. 1257-1408.

3. Боташева Т. Л., Черноситов А. В., Заводнов О. П., Гудзь Е. Б. Общая теория систем: живые системы, основные понятия, закономерности функционирования // Медицинский вестник Юга России. 2011. № 2. С. 51-56.

4. Бывшева М. В. Теоретические аспекты преемственности в системе образования // Психология и педагогика: методика и проблемы практического применения. 2011. № 22. С. 259-263.

5. Василенко Н. В. Институциональный подход к исследованию образования // Образование и наука. Известия УрО РАО. 2006. № 5 (41). С. 20-27.

6. Василенко Н. В., Шапкин В. В. Институционализм как методология исследования образования: монография. СПб.: РГПУ им. А. И. Герцена, 2005. 95 с.

7. Гинзберг А. С. // Центральный государственный исторический архив Санкт-Петербурга. Ф. 3133. Оп. 1.

8. Гинзберг А. С. К вопросу об общем и специальном образовании фармацевтов: докл. проф. А. С. Гинзберга на Рос. фармацевт. съезде. СПб.: Типо-лит. А. Винеке, 1913. 12 с.

9. Гинзберг А. С. К вопросу об однообразии систематики (с дидактической точки зрения) отделов фармации в современных медицинских и фармацевтических школах. СПб.: Тип. Я. Трей, 1902. 5 с.

10. Гинзберг А. С. О новых направлениях в вопросе фармацевтического образования // Фармацевтический журнал. 1915. № 42. С. 409-411; № 43. С. 419-421.

11. Гинзберг А. С. О постановке преподавания общей и прикладной химии в наших медицинских школах // Русский врач. 1902. № 20. С. 770-772.

12. Гинзберг А. С. О постановке преподавания общей и прикладной химии в наших медицинских школах: сообщ. на ХІ Съезде естествоиспытателей и врачей. СПб.: Тип. Я. Трей, ценз. 1902.10 с.

13. Гинзберг А. С. Очерк развития научной фармации в России за 200-летний период // Фармацевтический журнал. 1902. № 16. С. 271-272; № 21. С. 355-356; № 22. С. 365-366; № 23. С. 381-383.

14. Гинзберг А. С. Химико-фармацевтический факультет Ленинградского университета // Химико-фармацевтический журнал. 1925. № 2 (17). С. 13-14.

15. Гурьянова М. Н., Олейник Г. А. Исторические аспекты формирования профессиональной компетентности провизора в XIX - начале XX века // Проблемы социальной гигиены, здравоохранения и истории медицины. 2013. № 6. С. 48-50.

16. Коротеева Н. Н. Становление и развитие фармацевтического образования в России в XVII - начале XX в. // Ученые записки Российского государственного социального университета. 2010. № 2 (78). С. 161-166.

17. Кузнецов А. М. «Новый институционализм»: взгляд через призму дискурсивного анализа // Метод. 2014. № 4. С. 203-227.

18. Куликов В. А. Подготовка фармацевтических кадров в России в XVI-XIX веках // Вестник фармации. 2016. № 4 (74). С. 99-104.

19. Лопатина Н. Б., Пашанова О. В., Кривошеев С. А. Эволюция высшего фармацевтического образования в России // Вестник Воронежского государственного университета. Серия «Проблемы высшего образования». 2018. № 1. С. 80-87.

20. Наркевич И. А., Воробьева С. А., Васягина Ю. А., Комарков А. Ю. Под знаком столетия: сборник документов по истории СПХФУ. СПб.: Петербургский модный базар, 2019. 448 с.

21. Наркевич И. А., Звягин Ю. Ю., Воробьева С. А., Перелыгин В. В., Доброва Д. О. Он создал современного фармаколога // Формулы фармации. 2019. Т. 1. № 1. С. 95-102.

22. Национальная доктрина образования в Российской Федерации до 2025 г.: Постановление Правительства РФ от 4 октября 2000 г. № 751 // Собрание законодательства Российской Федерации (СЗРФ). 2000. № 41. Ст. 4089.

23. Панов П. В. Институционализм(ы): объяснительные модели и причинность // Полис. Политические исследования. 2015. № 3. С. 39-55.

24. Прохорова И. А. Теория систем и системный анализ: учебное пособие. Челябинск: Издательский центр ЮУрГУ, 2013. 49 с.

25. Селезнева Л. В. Исследования дискурса в современной лингвистике: опыт, направления, проблемы // Вестник Северо-Восточного федерального университета имени М.К. Аммосова. 2011. Т. 8. № 4. С. 119-124. 
26. Степанов С. В., Волгушева А. О., Завершинская Н. А. От Аптекарского приказа XVII в. до Санкт-Петербургского химико-фармацевтического университета: из истории высшего фармацевтического образования // Современные проблемы науки и образования. 2020. № 3. URL: http://science-education.ru/ru/article/view ?id=29773 (дата обращения: 21.06.2021).

27. Стратегия развития фармацевтической промышленности Российской Федерации на период до 2030 года [Электронный ресурс]. URL: https://yandex.ru/turbo/niejournal.ru/s/strategy-farm/ (дата обращения: 26.04.2021).

\section{Информация об авторах | Author information}

RU Воробьева Светлана Александровна ${ }^{1}$, д. филос. н., доц. Завершинская Наталья Александровна ${ }^{2}$, к. филос. н. Степанов Станислав Вячеславович ${ }^{3}$, к. филол. н.

1, 2, 3 Санкт-Петербургский государственный химико-фармацевтический университет

EN Vorobieva Svetlana Alexandrovna ${ }^{1}, \mathrm{Dr}$

Zavershinskaya Natal'ya Aleksandrovna ${ }^{2}, \mathrm{PhD}$ Stepanov Stanislav Vyacheslavovich ${ }^{3}, \mathrm{PhD}$

1, 2, 3 Saint Petersburg State University of Chemistry and Pharmacy

${ }^{1}$ svetlana.vorobieva@pharminnotech.com, ${ }^{2}$ nataliya.zavershinskaya@pharminnotech.com,

${ }^{3}$ stanislav.stepanov@pharminnotech.com

\section{Информация о статье | About this article}

Дата поступления рукописи (received): 12.04.2021; опубликовано (published): 30.06.2021.

Ключевые слова (keywords): дискурсивная деятельность; А. С. Гинзберг; высшее фармацевтическое образование; институциализация; педагогическая деятельность; discursive activity; A. S. Ginzberg; higher pharmaceutical education; institutionalisation; teaching activity. 